Revista de Antropología Social

ISSN: 1131-558X

http://dx.doi.org/10.5209/RASO.61857

\title{
Françoise Héritier: etnóloga, antropóloga social y defensora de la causa de las mujeres
}

\author{
Marie José Devillard
}

Recibido: 15 de abril de 2018 /Aceptado: 17 de junio de 2018

Resumen. A modo de homenaje a la carrera profesional de Françoise Héritier, el artículo repasa de manera necesariamente escueta su trayectoria y aportaciones etnográficas y antropológicas. Se enfatizan las continuidades temáticas, teóricas y epistémicas de su obra con los trabajos de Lévi-Strauss, al tiempo que se destaca la originalidad de sus investigaciones y contribución a una antropología del cuerpo. Asimismo, se aborda el compromiso de la autora con la posición de la mujer en el mundo social, así como su colaboración activa en un trabajo que pueda redundar en la consecución de una mayor igualdad entre los géneros.

Palabras clave: Héritier; universalidad; dominación masculina; mujer; cuerpo humano.

\section{[en] Françoise Héritier: Ethnologist, Social Anthropologist and advocate of women's cause}

\begin{abstract}
As homage to Françoise Héritier's career, this article reviews -in a necessarily brief wayher professional trajectory, and ethnographic and anthropological contributions. We stress the thematic, theoretical and epistemic continuities of her work with those of Lévi-Strauss, while we highlight the originality of her research and contribution to the anthropology of the body. Additionally, we underscore author's compromise with the position of the woman in the society as well as her active collaboration in a scholarly work that could result in achieving a greater equality among genders.
\end{abstract}

Keywords: Héritier; universalism; masculine domination; woman; human body.

Sumario. 1. Introducción. 2. Continuidades y rupturas. 3. Pasos hacia el cambio social. 4. Referencias bibliográficas.

Cómo citar: Devillard, M. J. (2018). Françoise Héritier: etnóloga, antropóloga social y defensora de la causa de las mujeres, en Revista de Antropología Social 27(1), 381-389.

\section{Introducción}

Resulta difícil rendir cuenta sucintamente de las dimensiones que singularizan la obra de Françoise Héritier (1933-2017). Aunque insatisfactorio, el título de este breve homenaje a su figura destaca algunas de sus facetas profesionales más sobresalientes. Siguiendo la diferenciación del campo de conocimiento de la antropología

\footnotetext{
$1 \quad$ Universidad Complutense de Madrid.

mj.devillard@cps.ucm.es
} 
social y cultural sugerida por Lévi-Strauss (1958[1945]), sería posible interpretarlo como una secuencia: el estudio etnográfico y etnológico precede a la labor más abstracta y generalizadora propiamente antropológica; siendo ambos la base imprescindible de la comprensión en la que tiene que apoyarse la intervención social.

Asimismo, una reconstrucción superficial de la trayectoria de la autora, guiada por lo que ella misma relata ex post en sus últimos libros -de corte más divulgativo y autobiográfico-, podría apoyar también una lectura unilineal; la simplicidad con la que relata sus primeros pasos, su formación emocional y afectiva hecha a retazos («de bric et de broc» [2017: 96]) y de «aventuras intelectuales» (2017: 110), la importancia de lo que considera azares y felices coincidencias que han marcado su recorrido profesional desde su inicio hasta el final pasando por su elección para sustituir a Claude Lévi-Strauss al frente del Laboratoire d'Anthropologie Sociale del Collège de France de Paris en 1983 («uno no se presenta al Colegio de Francia: lo presentan uno o dos profesores...» [Héritier, 2017: 121]²), darían fácilmente la impresión de un encadenamiento ascendente casi fortuito, más que de hacerse un lugar dentro del campo intelectual y científico donde, sin embargo, tuvo que imponerse debido, entre otras cosas, al hecho de ser mujer: «siempre tuve el sentimiento $-\mathrm{y}$ lo sigo teniendo con mis casi ochenta y cuatro años- de no estar en mi sitio, ser una intrusa, casi una usurpadora» (Héritier, 2017: 124).

Sin embargo, una mirada meramente cronológica o secuencial distaría de recoger lo más importante. Su manera de enfrentarse a su labor de científica social muestra más bien un caminar en el que, una vez superado el período inicial e iniciático de trabajo de campo en Burkina Faso, destaca una interpelación dialéctica y perseverante entre distintos saberes y niveles de experiencia, reflexión e implicación, prolongada a lo largo de toda su carrera profesional. Retomando sus palabras al recalcar la arbitrariedad de las divisiones de la realidad por la ciencia en contra de las cuales no dejó de posicionarse, se diría que ha convertido la tarea de «desenredar los hilos» -en vez de «zanjar (en) lo vivo» (Héritier, 2010b) - en una profesión, entendida esta con todos los matices del «profesar».

A falta de poder profundizar en una obra caracterizada por un alto nivel de especialización temática y tecnicismos, me limitaré más prosaicamente a señalar algunos rasgos y enseñanzas que caracterizan su trabajo. Tras una breve evocación de la importancia de la etnografía, destacaré las principales dimensiones de su obra que implican una clara continuidad con lo iniciado por Lévi-Strauss -análisis del parentesco, enfoque estructuralista y búsqueda de universales, énfasis en los modelos de pensamiento- seguidos de los aspectos que la diferencian en mayor o menor medida de sus planteamientos -importancia material y simbólica del cuerpo, estudio de la dominación masculina, defensa de los derechos de las mujeres, compromiso social-.

\section{Continuidades y rupturas}

Historiadora reconvertida luego a la antropología social bajo la incitación de Claude Lévi-Strauss, Françoise Héritier reivindicó siempre su condición de etnóloga. La etnología en Âfrica, en efecto, marcó su inicio en la disciplina y en el trabajo de campo entre los Samo, realizado a lo largo de un total de 7 años, si bien mediante

Todas las traducciones de las citas son mías. 
estancias discontinuas. Al respecto, son ilustrativas las palabras dedicadas a la forma de trabajar de su «madrina [de investigación]», la célebre Germaine Dieterlen entre los Dogon de Mali y junto a la cual experimentó «un modo de funcionamiento que fue el de los años 1930, pero que no era el de su generación, en la que se debía vivir como los miembros de la sociedad junto a los cuales se trabajaba». Recordar estas diferencias no es baladí, en tanto ilustra un modo de acercamiento que la autora no ha dejado de valorar de manera muy especial. «Tenía conciencia de que esta[s] diferencia[s] [vestimenta, modalidades de implementación de las técnicas de investigación...] simbolizaba[n] (...) sobre todo una diferencia de aproximación al otro y también una diferente concepción de la disciplina» (Héritier, 2017: 142-143). Aunque reconoce que la «cuasi-inmersión total» defendida en la década de los cincuenta no era posible, la suya no fue solo una base de conocimientos etnográficos fundamentales para su trabajo posterior sino una experiencia que, según confesión propia, fue motivo de asombro e, incluso, deslumbramiento y encandilamiento (Héritier, 2010b: 16): «...la tierra africana es sobre todo la que me ha permitido encontrarme en el campo con personas que he querido. «Sobre el terreno», «en el pueblo,», en la «selva», todas estas expresiones neocoloniales con las que se expresa la realidad de la vida del etnólogo» (Héritier, 2017: 136).

En cualquier caso, la evolución de sus investigaciones no fue casual ni meramente inductiva sino resultado de un trabajo reflexivo donde se han entremezclado cualidades y convicciones personales con un campo científico en plena evolución. Como ella misma recalcó, se posicionó a contra-corriente respecto a las investigaciones de corte culturalista, entonces en boga, cuyo afán era destacar la singularidad. «Lo que me importa no es la diferencia (...) sino la semejanza que se vuelve comprensible mediante las leyes de transformación, incluso estadísticas» (Héritier, 1981: 10). En cambio, la defensa de la legitimidad de la generalización se apoyaba tanto en la ascendencia intelectual como en el trabajo y enfoque estructuralista de Lévi-Strauss. Así, la cita anterior suena muy parecida al planteamiento que este había hecho con respecto al análisis de la relación de avunculado, décadas atrás (LéviStrauss, 1958[1945]).

La continuidad temática inicial de las investigaciones con Lévi-Strauss está bien ilustrada por la cantidad de publicaciones dedicadas al parentesco y a las alianzas matrimoniales (Héritier, 1981, 1994a; Héritier y Copet-Rougier, 1990, 1991, 1993, 1994, 1995) así como al incesto (Héritier, 1994b; Héritier, Cyrulnik y Naouri, 1994). Sin embargo, el peso del análisis de las relaciones entre hombres y mujeres fue tomando progresiva y paralelamente cada vez más protagonismo (2002, 2005a, 2005b, 2008a, 2010a) así como, estrechamente ligado a aquel, el papel del cuerpo en la construcción simbólica y social de lo masculino y de lo femenino (Héritier, 1994a, 1996b; Héritier y Xanthakou, 2004). Lo cual constituyó, durante 18 años, la base de sus cursos en el Collège de France de lo que se ha dado en llamar Antropología del cuerpo ${ }^{3}$. Pero solo es en Retour aux sources (2010b) cuando retoma y publica unos escritos de 1978-1979 que, pese a que fueran inicialmente destinados a «poner orden en las informaciones» disponibles sobre los Samo, condensaban ya -a su entender- las «ideas fuerza» de los

\footnotetext{
En cualquier caso, Héritier se cuida de desmarcar su trabajo de una antropología de los sexos cuyo desarrollo considera, sin embargo, necesario. Advierte que nunca fue su objeto de investigación propiamente dicho. El nexo -y potencial fuente de confusión- radicaría en que ha indagado sobre cuestiones, como la «reproducción, la inscripción corporal, los componentes de la persona, los humores...» (Héritier, 2009: 86), que están relacionadas con aquella.
} 
trabajos ulteriores, constituyendo así el libro una especie de monografía que articula las dimensiones trabajadas en detalle en otros lugares.

Retrospectivamente y sin que -dados los conocimientos etnológicos actuales- ella considere a los Samo como un caso excepcional (Héritier, 2009: 227), señala refiriéndose a lo que aprendió entre ellos que «todo estaba aquí [dans l'oeuf], todo aquello que iba a convertirse en mis principales temas de reflexión teórica» (Héritier, 2010b: 17). Lévi-Strauss había centrado su trabajo sobre las preferencias matrimoniales definidas en función de los vínculos de parentesco (dando lugar a lo que denominó «estructuras elementales»). Retomando el hilo, ella exploró el funcionamiento de uno de los posibles casos de «sistema semi-complejo» (en el que la elección del cónyuge está vinculada a un sistema terminológico de tipo Crow y Omaha) -tema que se consideraba entonces como un paso hacia el conocimiento de los llamados «sistemas complejos» (en los que intervienen otras dimensiones: económicas, políticas, religiosas...), todavía no estudiados en detalle-. Inicia L'exercice de la parenté, dedicado a la exposición de sus primeros resultados, presentando su empresa como sigue:

He partido no solo del postulado de que una lógica general está implicada en la relación entre diferentes tipos terminológicos de parentesco, lógica derivada de la invariante constituida por el dato universal del orden biológico, sino también de una segunda íntimamente ligada a la primera. Un sistema-tipo terminológico es él mismo una estructura que expresa necesariamente algo con respecto a la relación entre sexos, generaciones, mayores y menores, ya que manifiesta una de estas figuras posibles de la combinación de este dato real; escenifica una visión del mundo particular. (Héritier, 1981: 11).

Gracias a la recopilación sistemática de genealogías reales y a su procesamiento por ordenadores -lo que de por sí ya representó una innovación en la materia-, puso en evidencia que no estamos frente a preferencias matrimoniales. Por el contrario, el matrimonio se definía dentro de las exiguas posibilidades que dejaban unas prohibiciones que no concernían ya únicamente a los individuos sino in extenso a los grupos de filiación y afines. Este análisis fue, además, la base de un trabajo más detallado de lo que calificó como «incesto de segundo tipo»-relación de dos hermanas con un mismo hombre- cuya prohibición considera necesaria para el funcionamiento de los sistemas semi-complejos (Héritier, 1981, 1994). Paralelamente puso de relieve cómo las prohibiciones matrimoniales no están basadas solo en el parentesco sino también en las representaciones de la formación del cuerpo humano, muy especialmente en torno a las aportaciones paterna y materna de los diferentes humores corporales esperma, sangre, leche--. La constatación de que el sexo femenino está sistemáticamente «considerado como antinómico del masculino» y que los menores detalles de la vida cotidiana «traducen la hegemonía del principio masculino» (Héritier, 2010b: 20) se apoyará así en el análisis comparativo de estas mismas conexiones simbólicas.

Volviendo, pues, la mirada hacia la herencia estructuralista, es de resaltar cómo la puesta en evidencia de elementos constantes atraviesa toda la obra, incluidas las publicaciones últimas, más ensayísticas y personales, como Le sel de la vie (Héritier, 2012) o Le goût des mots (Héritier, 2013). Así, por ejemplo, del primer libro que recoge hechos menudos y en apariencia anodinos de su vida, dice retrospectivamente que «se trataba de algún modo de hacer aflorar lo permanente bajo lo contingente, 
y lo universal detrás de lo individual» (Héritier, 2017: 11). Los textos reunidos por Salvatore D'Onofrio en Une pensée en mouvement (Héritier, 2009) recogen bien esta continuidad. Ni que decir tiene, que el planteamiento no se opone a la diversidad cultural o a los particularismos ni excluye el cambio social. Se trata más bien de encontrar, como ya propusiera Lévi-Strauss en su momento, lo que es común (similitudes y diferencias) detrás de la variedad de las prácticas y de las representaciones sociales conocidas. Resumiendo mucho el tema y corriendo el riesgo de simplificarlo, se pueden destacar en la obra de Françoise Héritier aspectos de diverso rango pero encadenados entre sí, en torno a la constatación de la universalidad histórica de la dominación masculina -jerarquización, inferiorización, vulneración, discriminación de las mujeres, imputación de la esterilidad...-, y a los hechos que permiten explicar las regularidades de estas ideas, pese a la diversidad de sus formas. En todo ello, no hay naturalismo ni esencialismo. La diferencia de los géneros no está dada, es un artefacto, una representación social construida. La dominación es, pues, política, una relación social que no está fundada en cualidades naturales sino derivada de una ordenación simbólica.

«Lo masculino»y «lo femenino» son constructos mentales. Se parte del presupuesto de que el sistema de pensamiento dual se elabora utilizando un dato existente primordial, de orden biológico. La formulación recubre aspectos de diferente índole. De un lado, se apunta la importancia de las representaciones sociales y de los sistemas de pensamiento. «La ideología -recuerda en Retour aux sources- es la realidad, y a la vez pensamiento que actúa y pensamiento interpretativo. (...) Está en acción en el comportamiento del que actúa y en la interpretación de la acción que hace el observador» (Héritier, 2010b: 27). Por otro lado, la disposición cognitiva que permite establecer relaciones (identificando y diferenciando), se materializa aquí en la construcción simbólica de la diferencia sexuada. Desde esta perspectiva, la atención última no está centrada en el funcionamiento mental que subyace a la ordenación social -como fuera el caso de la puesta en evidencia de las «estructuras mentales» comunes en Lévi-Strauss- sino en el material inmediato del que se parte. Aquí está, según creo, una de las principales rupturas con su mentor.

Asimismo, el papel atribuido a la «observación» es una constante que responde a presupuestos tanto cognitivos - predisposiciones para conocer- como epistémicos y teóricos. En contra del naturalismo, la autora argumenta que todas las configuraciones culturales de prácticas, ideas y representaciones sociales, derivan de la aptitud para conocer de todo ser racional gracias a la observación, análisis y comparación de los hechos. Concretamente, «existen raíces corporales del pensamiento, lo cual permite alcanzar un nivel fundamental que es universal: los mismos datos de la percepción, interpretados por los mismos sistemas neurovegetativos, cerebrales y emocionales» (Héritier, 2010b: 184). Héritier define así lo que llamara el «zócalo duro de observaciones primordiales» (Héritier, 2002: 18) o, también, los «topes» [butoirs] del pensamiento, «irreductibles e imposibles de esquivar» (Héritier, 2010b: 23); aquello «más allá de lo cual no se puede ir y con lo que hay que transigir» (Héritier, 2015: 61). Unos topes [butoirs] del pensamiento, pues, con los que se han encontrado «el $[\mathrm{H}]$ ombre en sus inicios (...) y en todos los tiempos, incluidos nuestros días» (Héritier, 2010a: 23).

Entre los topes [butoirs] más destacados por la autora, y que funcionan conjuntamente, citamos: junto a la inevitabilidad de la vida y la muerte y el orden de las generaciones, la necesidad de la copulación y de que haya mujeres para la existencia de 
hijos e hijas, el hecho de que ellas tengan la capacidad de producir tanto lo idéntico -hijas- como lo diferente -hijos-... La «valencia diferencial de los sexos», se debe, pues, «menos a un hándicap femenino (fragilidad, menor peso, menor tamaño, hándicap de los embarazos o de la lactancia) que a la expresión de la voluntad de controlar la reproducción de parte de quienes no poseen este poder tan peculiar» (Héritier, 2009: 94). Dicho de otro modo, la «universalidad» de la dominación masculina -el paso de la diferencia a la dominación- surge de la necesidad de contrarrestar el efecto del zócalo duro de la humanidad, a saber, que «solo las mujeres hacen los hijos» $\mathrm{y}$, por consiguiente, de controlar la potencial superioridad femenina.

Igualmente, la atención complementaria a los componentes corporales permite identificar otros elementos distintivos o topes [butoirs] del pensamiento, que explican las similitudes constatables entre las representaciones en las que se apoya general y simbólicamente la inferiorización de las mujeres: el cuerpo humano transporta líquidos, unos calientes, otros fríos; la sangre es fundamental en la generación; los hombres fabrican esperma y las mujeres leche, pero esta no tiene las mismas potencialidades que aquel; además las mujeres sangran, una pérdida que es generadora de peligros de los cuales los varones tienen que premunirse...

En definitiva, la autora muestra -apoyándose en la comparación de datos procedentes de diferentes mundos sociales y épocas históricas- cómo, más allá de la diversidad de configuraciones culturales históricamente conocidas, se vuelven a encontrar combinaciones de los mismos elementos básicos, que desembocan a su vez en prácticas y representaciones, si no iguales, al menos similares y con semejantes consecuencias. En suma, y retomando una de las múltiples formulaciones de Héritier, la argumentación básica consiste en afirmar que:

tanto respecto a la construcción de las relaciones de parentesco (terminología, filiación, alianza) como respecto a las relaciones de género, de la persona, de la procreación, etc...todo parte del cuerpo, de unidades conceptuales inscritas en el cuerpo, en lo biológico y lo fisiológico, observables, reconocibles, identificables en todos los tiempos y lugares; estas unidades ajustadas y recompuestas de acuerdo a diferentes fórmulas lógicas reconocibles, pero posibles porque son pensables, según las culturas. Por tanto, destaco una inscripción necesaria en lo biológico, pero sin que haya una traducción única y universal de estos datos elementales (Héritier, 2009: 92).

Por ende, al incorporar las prácticas y los sistemas de pensamiento, se naturalizan de tal modo que todos y todas tienden a reproducirlo y a reforzarlo. «Es particularmente difícil para el sexo dominante renunciar a una situación llena de prerrogativas y ventajas en provecho de un compartir [partage] razonado.» (Héritier, 2010a: 39). No obstante, y aunque las mujeres hayan sido y sean permanentemente las principales víctimas de este sistema de pensamiento, eso no las exime completamente de la responsabilidad de perpetuar los esquemas culturales que las sujetan.

\section{Pasos hacia el cambio social}

Pero el hecho de constatar la generalización de determinados temas, imágenes y prácticas sociales no excluye la posibilidad de que esas prácticas y representaciones 
sociales evolucionen. Si bien las diferencias sexuadas pertenecen al orden de los hechos, no tienen por qué acompañarse de -ni justificar- la jerarquía. Las intervenciones públicas y obras de divulgación de Françoise Héritier (1999, 2001, 2008a, 2008b, 2009, 2015) abogan en este sentido.

A este respecto, su tratamiento de los derechos humanos es iluminador. La autora constata que ningún derecho es «tan controvertido como la igualdad entre los sexos, es decir, el simple reconocimiento de que las mujeres participan de lo humano al igual que los varones», y que siempre es «en relación a la extensión de los derechos humanos a las mujeres cuando se acude al argumento del relativismo cultural» (Héritier, 2010a: 21). Asimismo, rechaza la idea de que dicha extensión al conjunto de las poblaciones sea una injerencia de corte colonialista, y defiende que no hay cabida para el relativismo cultural. El cambio social pasa por la ruptura con las representaciones «universales» $\mathrm{y}$ «arcaicas» transmitidas de generación en generación, y que sobreviven aún hoy. En última instancia, lo «universal» es socio-histórico y remite a constructos generalizados, y no a realidades eternas y naturales. Como ya se ha señalado, uno de sus principales objetivos de investigación consistió precisamente en comprender lo que pudo originar dicha generalización en el orden simbólico (Héritier, 2002, 2010a).

Ante eso, la autora recuerda con insistencia que el progreso de los conocimientos proporcionan los instrumentos de ruptura necesarios para potenciar una mayor igualdad entre géneros: el descubrimiento de los gametos en el siglo XVIII y del juego cromosómico en el XX han dejado al descubierto la aportación compartida del varón y de la mujer; el derecho a la contracepción marca un reconocimiento de la mujer como persona plena. Constata también la evolución de la sociedad: la disociación de la sexualidad de la procreación o el reconocimiento de nuevos roles a las mujeres. En este sentido, y consecuentemente, presenta la plena igualdad entre hombres y mujeres -tarea a la que todos tienen que concurrir- como un horizonte pensable aunque, sin duda, muy lejano (Héritier, 2002: 190).

Por muy difícil y poco probable que entrevea el total reconocimiento social de la igualdad de género, Françoise Héritier hace alguna propuesta que incluye principalmente «modificaciones con respecto a la mirada y a los hábitos mentales». Refiriéndose a usos lingüísticos comunes en nuestra sociedad, advierte así de la necesidad de vigilar el valor semántico de las palabras; dejar de considerar a las mujeres como «una categoría sociológica minoritaria semejante a la edad, el color, la religión, la discapacidad o la etnia»; así como rehusar hablar de un ser humano asexuado puesto que se le suele identificar con el género masculino. Más generalmente y a modo de conclusión, aconseja un plan de actuación aplicable a todos consistente en «empeñarse en desvelar, dar a comprender mecanismos invisibilizados, abrir los ojos hasta ahora cerrados; ayudar de manera concreta, hasta en los niveles más humildes, a la realización de un paso hacia la igualdad.» (Héritier, 2002: 190-191).

Por breve que sea la referencia y por controvertidas que hayan sido algunas de sus intervenciones, en tanto que está ligada a esta problemática, es imprescindible completar el cuadro mencionando la participación activa de Héritier en calidad de experta en foros y organismos dedicados a cuestiones importantes a las que se enfrentan los mundos sociales contemporáneos: contracepción, violencia contra la mujer, reconocimiento social de la homosexualidad, matrimonio gay, gestación subrogada, manipulación genética y bioética... temas de los que varias publicaciones (Héritier, 1996b, 1999b, 2001, 2002, 2008a, 2009, 2010a, 2015) se hacen eco. Entre dichos 
organismos destaca, a instancias del presidente de la República, François Miterrand, su intervención en el Alto Consejo de la Población y de la Familia (Haut conseil de la population et de la famille) como presidenta del Consejo Nacional del Sida (19891995), seguida luego por su participación en el Comité Consultativo Nacional de Ética o, también, durante dos años, en el Consejo Económico y Social. Al respecto Héritier manifestaba su convicción de que, pese a las dificultades, es «absolutamente necesario actuar sobre lo político» aportando una mirada diferente de la habitual, es decir, informada por los conocimientos y el distanciamiento cultural que no pueden tener los hombres y las mujeres que se dedican a ello (Héritier, 2008a: 92).

En suma, si relacionamos su intervención en cuestiones de gran trascendencia societal con su trayectoria profesional, se puede concluir -a grandes rasgos- que Françoise Héritier ha puesto sus conocimientos de etnógrafa y antropóloga social al servicio de la defensa de las mujeres, desvelando precisa y fundamentalmente unos mecanismos de la dominación masculina cuyos resortes simbólicos, corporales y prácticos, quedan perdurablemente invisibilizados. Y lo hizo con el convencimiento de la necesidad de aportar herramientas de comprensión que ayuden si no a hacer desaparecer totalmente la desigualdad de género, al menos a subvertirla.

\section{Referencias bibliográficas}

Héritier, Françoise (1981). L'exercice de la parenté. Paris: Gallimard.

- (1994). Les deux soeurs et leur mère. Anthropologie de l'inceste. Paris: Éditions Odile Jacob.

- (1996a). De la violence. Paris: Éditions Odile Jacob.

- (1996b). Masculin / féminin. La pensée de la différence. Paris: Éditions Odile Jacob. [(1996). Masculino/femenino: el pensamiento de la diferencia. Barcelona: Ariel].

- (1999a). De la violence II. Paris: Éditions Odile Jacob.

- (1999b). Contraception: contrainte ou liberté?. Paris: Éditions Odile Jacob.

- (2001). Maternité, affaire privée, affaire publique. Paris: Bayard.

- (2002). Masculin-féminin 2, Dissoudre la hiérarchie. Paris: Éditions Odile Jacob. [(2007). Masculino/femenino II: disolver la jerarquía. Buenos Aires: FCE].

- (2005a). Le féminin en miroir: entre Orient et Occident. Paris: Campagne Première.

- (2005b). Hommes, femmes, la construction de la différence. Paris: Le Pommier.

- (2008a). L'identique et le différent. Entretiens avec Caroline Broué. Paris: L'Aube.

- (2008b). Pour une anthropologie symbolique du corps (À voix haute). Paris: Gallimard, CD.

- (2009). Une pensée en mouvement. Paris: Éditions Odile Jacob.

- (2010a). «Les droits des femmes dans la controverse entre universalité des droits de l'homme et particularité des cultures» en J.L. Amselle, L. Guirlinguer, F. Héritier et al (Eds.) Diversité culturelle et universalité des droits de l'homme. Paris: Éditions Cécile Defaut.

- (2010b). Retour aux sources. Paris: Galilée.

- (2012). Le Sel de la vie. Paris: Éditions Odile Jacob. [(2012). La sal de la vida. Madrid: Editorial Aguilar.]

- (2013). Le goût des mots. Paris: Éditions Odile Jacob.

- (2015). La différence des sexes explique-t-elle leur inégalité?. Paris: Bayard.

- (2017). Au gré des jours. Paris: Éditions Odile Jacob. 
Héritier Françoise; Copet-Rougier Élisabeth (1990). Les complexités de l'alliance. Tome 1: Les systèmes semi-complexes. Paris: Éditions des archives contemporaines.

- (1991). Les Complexités de l'alliance. Tome 2: Les systèmes complexes d'alliance matrimoniale. Paris: Éditions des archives contemporaines.

- (1993). Les Complexités de l'alliance. Tome 3: Économie, politique et fondements symboliques (Afrique). Paris: Editions des archives contemporaines.

- (1994). Les Complexités de l'alliance. Tome 4: Économie, politique et fondements symboliques. Paris: Éditions des archives contemporaines.

- (1995). La parenté spirituelle. Paris: Éditions des archives contemporaines.

Héritier, Françoise; Cyrulnik, Boris; Naouri, Aldo (1994). De l'inceste. Paris: Éditions Odile Jacob. [(1995). Del incesto. Buenos Aires: Ediciones Nueva Visión].

Héritier, Françoise; Xanthakou Margarita (Dirs.) (2004). Corps et affects. Paris: Éditions Odile Jacob.

Lévi-Strauss, Claude (1949). Les structures élémentaires de la parenté. Paris: Mouton.

- (1958[1945]). «L'analyse stucturale en linguistique et en anthropologie» en Anthropologie structurale. Paris: Plon. 